\title{
Cross-sectional and longitudinal growth patterns in osteogenesis imperfecta: implications for clinical care
}

\author{
Emily L. Germain-Lee ${ }^{1,2}$, Feng-Shu Brennen', Diana Stern' ${ }^{1}$ Aditi Kantipuly', Pamela Melvin', Mia S. Terkowitz' and \\ Jay R. Shapiro ${ }^{1,3}$
}

BACKGROUND: There is strikingly limited information on linear growth and weight in the different types of osteogenesis imperfecta (OI). Here, we define growth patterns further with the intent of implementing appropriate adaptations proactively.

METHODS: We report cross-sectional anthropometric data for 343 subjects with different Ol types (144 children, 199 adults). Longitudinal height data for 36 children ( 18 girls, 18 boys) with Ol type I and 10 children ( 8 girls, 2 boys) with OI type III were obtained.

RESULTS: In all cases, the height Z-scores were negatively impacted, and final height Z-scores were impacted the most. In type I, the growth velocities taper near puberty, and there is a blunted pubertal growth spurt. The growth velocities of children with type III decelerate before age $5 \mathrm{y}$; poor growth continues without an obvious pubertal growth spurt. Obesity is a concern for all patients with Ol, with type III patients being the most affected.

CONCLUSION: The linear growth patterns, in addition to the marked increase in weight over time, indicate a need for lifestyle modifications early in childhood, especially a need for weight control. Further definition of the anthropometric measures in Ol enables patients to begin modifications as early as possible.

\footnotetext{
O
} steogenesis imperfecta (OI) comprises a group of heritable connective tissue disorders generally defined by skeletal fragility, recurrent fractures, low bone mass, and short stature. The vast majority of OI cases $(\sim 90 \%)$ are the result of dominant mutations in either of the two type I collagen genes, COL1A1 or COL1A2 (1). A rapidly growing list of recessive gene mutations has emerged, which account for the remaining $5-10 \%$ of OI cases although, with a few exceptions (e.g., SERPINF1, IFITM5, WNT1, SP7), most of these genes are involved in the trafficking or complex post-translational processing of type I collagen (2). Five types of OI, based largely on the Sillence classification system that was originally outlined 35 $y$ ago, comprise the majority of patients and are the groups that we investigated in this study (3). In order of increasing severity, the five phenotypic classifications of OI are type I (classic, nondeforming OI with blue sclerae), type IV (common variable OI with normal or blue sclerae), type V (OI with ossification in interosseous membranes), type III (progressively deforming OI with normal or blue sclerae), and type II (perinatally lethal OI). The majority of the rare, recessive types of OI and newly discovered noncollagen molecular defects, which had previously been assigned their own OI types, have clinically similar phenotypes to OI types II and III (1-4).

Impaired linear growth and short stature are salient features of severe OI. These features are also typical of many children with mild to moderate OI. However, the etiology of growth retardation in patients with OI is not completely understood. Historically, the poor growth in OI is more notable in patients with qualitative defects in collagen synthesis than in those patients with quantitative defects in whom one-half normal amounts of type I collagen are secreted into the extracellular matrix (5-13). The patterns of growth in OI have been analyzed most extensively in types I, III, and IV OI. Children and adults with type I OI can have normal stature or only minimally affected height reductions whereas those with type III OI uniformly have severe short stature accompanied by numerous fractures and extensive bony abnormalities. Patients with type IV OI have mild to moderate short stature with a variable phenotype in terms of linear growth and extent of fractures although always shorter than their genetic target heights $(5,12,14-18)$. Several studies have examined vertebral height after bisphosphonate treatment during varying periods of linear growth and have found conflicting results as to the efficacy of this therapy (19-22), although there are no prospective studies to date that have examined the effect on final height in the OI population. Because bisphosphonates are often given at different ages and over varying durations of time, there is often limited ability to make any general conclusions about treatment efficacy. The issue of weight has only begun to be addressed in the OI population. In a small cohort of patients with OI, there was a higher BMI in type III OI than in type I OI and normal controls and in a larger study an association

\footnotetext{
'Bone and Osteogenesis Imperfecta Department, Kennedy Krieger Institute, Baltimore, Maryland; ${ }^{2}$ Department of Pediatrics, Division of Pediatric Endocrinology, Johns Hopkins University School of Medicine, Baltimore, Maryland; ${ }^{3}$ Department of Physical Medicine and Rehabilitation, Johns Hopkins University School of Medicine, Baltimore, Maryland. Correspondence: Emily L. Germain-Lee (GermainLee@kennedykrieger.org)

Received 12 January 2015; accepted 12 August 2015; advance online publication 2 December 2015. doi:10.1038/pr.2015.230
} 
was found between being overweight/obese and OI type, with a higher percentage of energy intake and obesity in OI type III compared to types I and IV $(23,24)$.

Here, we report both cross-sectional and longitudinal height and weight data for 343 patients with different types of OI including 144 children and 199 adults, the largest cohort examined to date. We have found that in addition to compromised height and linear growth, obesity is quite prevalent. The purpose of this study was to investigate thoroughly the growth patterns for both height and weight in different OI types and ultimately to integrate a more detailed assessment of these parameters into clinical management by being able to predict height and weight outcomes based on the growth patterns and thereby implement interventions as early as possible.

\section{RESULTS}

\section{Height Z-Scores in Children and Adults With OI}

Height Z-scores were calculated for both children and adults for OI types I, III, IV, and V. Average pediatric height Z-scores are shown in Table 1 as the mean height Z-score for age along with the mean age and age range for each OI type. Average adult height $Z$-scores are also shown in Table 1 as the mean height $\mathrm{Z}$-score for age along with the mean age and age range for each OI type. Graphic representation of these data with the differences between OI types is shown in Figure 1 and reveals a similar pattern in children compared to adults. Overall, the mean height Z-scores in adults with OI were lower than in children for the corresponding OI type, with type III and type $\mathrm{V}$ being significantly lower $(P<0.05)$ compared to the mean height Z-score in children with types III and V.

In order to assess whether there were any differences in height Z-scores based on the younger half of the group of children vs. those who were older, subjects who were less than 11 $\mathrm{y}$ of age were analyzed vs. those who were 11-19 y of age (i.e., less than $20 \mathrm{y}$ of age) as shown in Figure 2 (children were followed over time and some, but not all, have height Z-scores for both age ranges). This division by age also separates the subjects by pubertal status to a large degree (i.e., prepubertal vs. pubertal). The children in both groups had similar height Z-scores and also similar patterns based on the OI type, and these replicated the pattern seen in the group as a whole. The specific Z-scores are shown in Table 2 for the two age groups.

Our data compared to those in the literature are detailed in Table 3 and show the largest cohort of both children and adults with OI examined to date (total $=343$ ). The other studies examined between 15 to 125 subjects (see tables), with only one other study examining type V OI (25). In our cohort, the children with type I and type V OI had the best height Z-scores. All the other studies detailed in Table 3 also revealed the best height Z-scores for type I OI, and the one other study that examined type V OI found a shorter population overall than our cohort of type V. Children with type IV OI had lower height Z-scores than type I or type $\mathrm{V}$ as children, with the type III OI children having the worst height Z-scores. The same trend was observed in our study for adults with OI, with our study being one of the two studies of adult heights and the only one to have examined adult height $\mathrm{Z}$-scores in subjects with type V OI (Table 3 ).
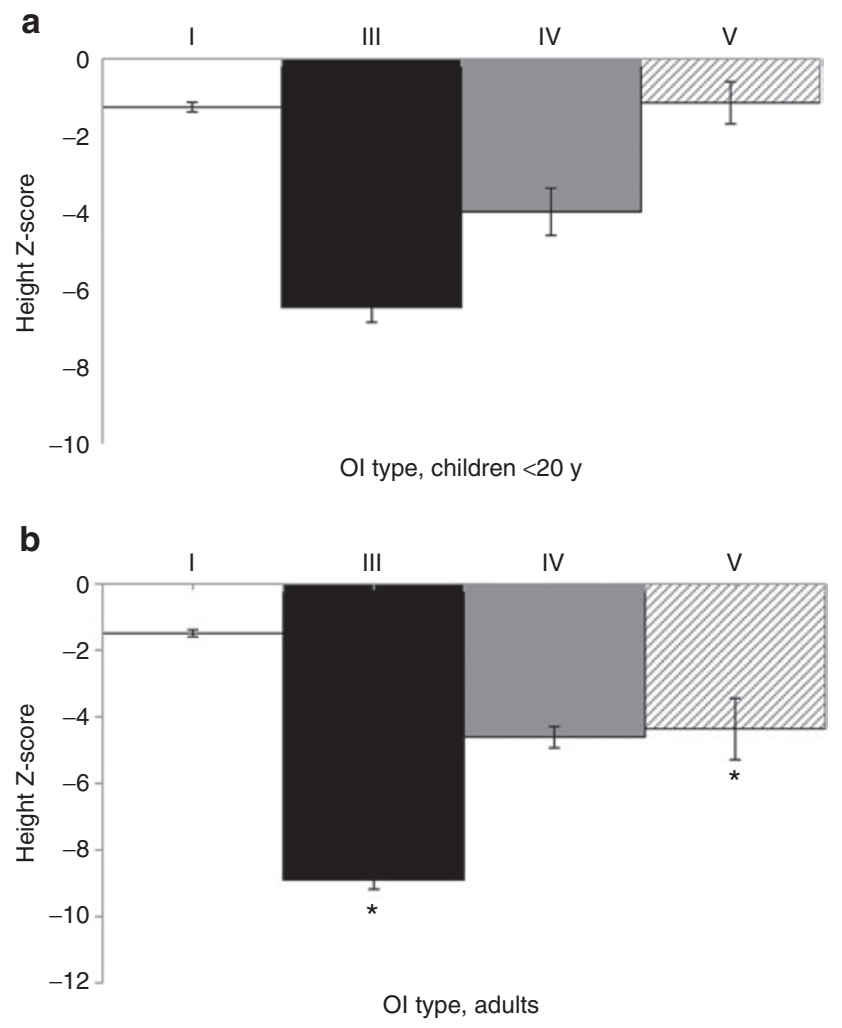

Figure 1. Average height Z-scores \pm SEM for children and adults: osteogenesis imperfecta (OI) type I (white), III (black), IV (gray), and V (cross hatched). (a) Children $<20$ y of age: type I $(-1.26 \pm 0.13, n=95)$, type III $(-6.45 \pm 0.39, n=34)$, type IV $(-3.98 \pm 0.61, n=10)$, and type V $(-1.15 \pm 0.55, n=5)$. (b) Adults $\geq 20$ y: type I $(-1.49 \pm 0.10, n=128)$, type III $(-8.90 \pm 0.28, n=36)$, type IV $(-4.61 \pm 0.32, n=26)$, and type V $(-4.36 \pm 0.92, n=9) .{ }^{*}$ indicates statistically significant differences between adult cohort in OI types III and V vs. the respective cohorts in children.

Table 1. Height Z-scores \pm SEM (and range) according to Ol type

\begin{tabular}{|c|c|c|c|c|c|c|}
\hline \multirow[b]{2}{*}{ Ol type } & \multicolumn{3}{|c|}{ Children } & \multicolumn{3}{|c|}{ Adults } \\
\hline & $N(\mathrm{~F} / \mathrm{M})$ & Age (years) & Height Z-score & $N(\mathrm{~F} / \mathrm{M})$ & Age (years) & Height Z-score \\
\hline I & $95(48 / 47)$ & $7.6(0.3-18.8)$ & $-1.26 \pm 0.13(-6.35$ to 1.1$)$ & $128(83 / 45)$ & $43.0(20.4-77.4)$ & $-1.49 \pm 0.10(-5.14$ to 1.49$)$ \\
\hline IV & $10(5 / 5)$ & $8.9(1.5-19.7)$ & $-3.98 \pm 0.61(-7.08$ to -1.51$)$ & $26(15 / 11)$ & $44.2(25.1-72.8)$ & $-4.61 \pm 0.32(-7.99$ to -1.88$)$ \\
\hline V & $5(1 / 4)$ & $5.8(0.7-11.1)$ & $-1.15 \pm 0.55(-3.16$ to -0.17$)$ & $9(3 / 6)$ & $40.8(22.1-58.0)$ & $-4.36 \pm 0.92(-8.89$ to -1.39$)$ \\
\hline
\end{tabular}

Ol, osteogenesis imperfecta. 


\section{Longitudinal Growth in Children With OI}

Longitudinal height data for 36 subjects (18 girls and 18 boys) with OI type I and 10 subjects ( 8 girls and 2 boys) with OI type III were obtained, as shown in Figure 3 and as compared to the percentile curves for the general population. In type I, the mean height velocity standard deviation score (HVSDS) is -0.15 , and the growth velocities taper near the onset of puberty. There is a mild blunting of the pubertal growth spurt with a mean pubertal HVSDS of -1.35 . The growth velocities of children with type III begin to decelerate before age $5 \mathrm{y}$ with a mean HVSDS of -2.93 for ages $2-8$ y; the poor growth continues through puberty without an obvious pubertal growth spurt (HVSDS of -3.74). There are no data to date in which

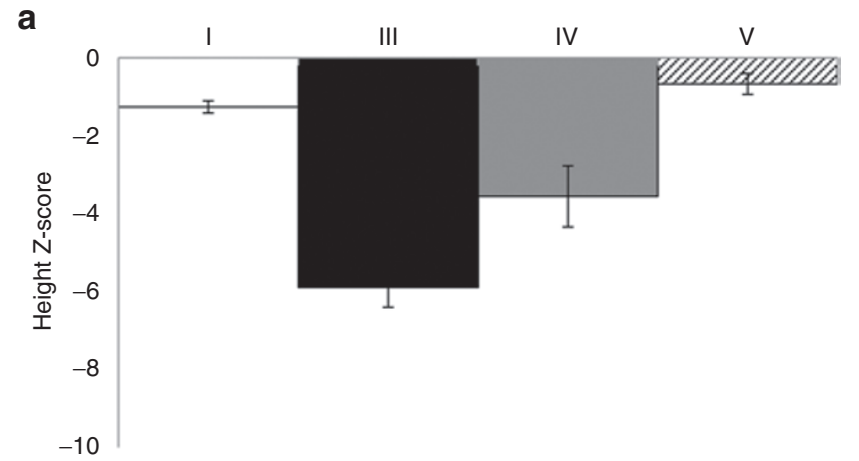

Ol type, children $<11$ y

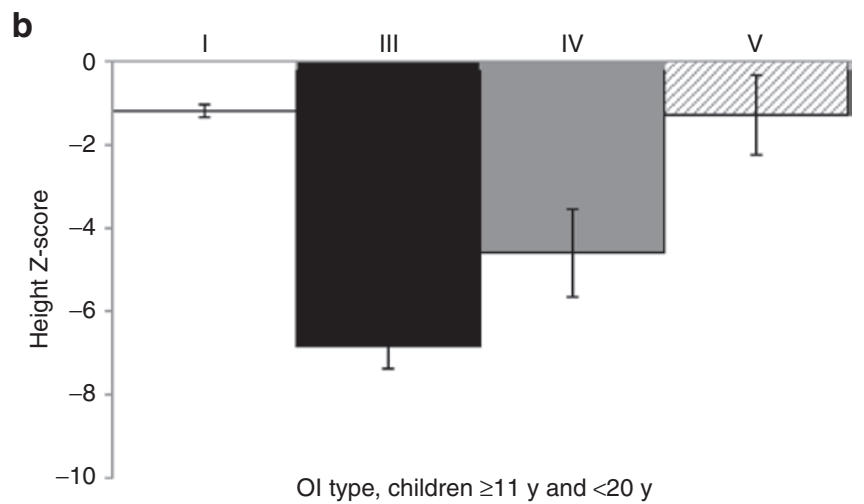

Figure 2. Average height Z-scores \pm SEM for children $<11$ y of age and children $\geq 11$ y to $<20$ y of age: osteogenesis imperfecta (OI) type I (white), III (black), IV (gray), and V (cross hatched). (a) Children <11 y old: type I $(-1.27 \pm 0.16, n=73)$, type III $(-5.89 \pm 0.51, n=18)$, type IV $(-3.56 \pm 0.79$, $n=6)$, type $V(-0.67 \pm 0.27, n=4)$. (b) Children $\geq 11$ y old to $<20$ y old: type I $(-1.19 \pm 0.15, n=33)$, III $(-6.82 \pm 0.55, n=18)$, IV $(-4.60 \pm 1.05, n=4)$, and $\mathrm{V}(-1.29 \pm 0.96, n=3)$. Note: There is overlap for some children who are within both age subgroups, as they were followed longitudinally. the evolution of puberty and details of the pubertal growth spurt have been examined in OI. Our data based on the growth curves reveal either an absent or suboptimal pubertal growth spurt even in the face of normal pubertal advancement associated with appropriate Tanner stage progression.

\section{Obesity}

Obesity is also a concern for all patients with OI, with type III patients being the most severely affected. When taller than approximately $100 \mathrm{~cm}$, the weights of the subjects in our study were significantly increased over time for all ages and for both genders based on height-for-weight growth curves with the height-for-weight curve for the general population superimposed, as shown in Figure 4. The increases in weights are dramatic for OI types I, III, and IV (with type V having too few subjects to examine by gender in this manner).

\section{DISCUSSION}

The purpose of this study was to identify growth patterns in OI of various types in a large cohort, as detailed anthropometric measurements have not been given sufficient attention. In addition, there is limited information on weight in the different OI types. Hence, we examined the height Z-scores, linear growth velocity, and weight of 344 children and adults with OI types I, III, IV, and V.

Our study documents the negative effect of OI on height Z-scores and linear growth velocity in the largest group of OI subjects examined to date. Lund et al. (5) first documented height Z-scores for adults with OI (Table 3) in 1999 and reported that heights of patients with OI are compromised compared to the heights of unaffected first-degree relatives, suggesting that the collagen defect may be the primary cause of short stature. Marini et al. (26) noted that children with type I OI grow parallel to but below the normal growth curve, while children with more severe disease (type III or type IV) plateau in their growth as early as age 6 or $7 \mathrm{y}$ for reasons as yet unknown. Although patients with OI can be GH deficient, $\mathrm{GH}$ deficiency does not appear to be the mechanism underlying growth retardation in the vast majority of patients with OI based on GH stimulation testing in this condition (18).

Clearly, in moderate to severe OI, the poor linear growth and short stature are greatly impacted by the skeletal abnormalities such as lower limb bowing and extremity fractures, scoliosis, vertebral compression, and growth plate disintegration ("popcorn epiphyses" typical of severe OI) (27-29). However, it is evident that growth can be impaired even in the absence

Table 2. Height Z-scores \pm SEM (and range) in children according to Ol type

\begin{tabular}{|c|c|c|c|c|c|c|}
\hline \multirow[b]{2}{*}{ Ol type } & \multicolumn{3}{|c|}{ Children $<11$ y } & \multicolumn{3}{|c|}{ Children $\geq 11 y$ and $<20 y$} \\
\hline & $n(\mathrm{~F} / \mathrm{M})$ & Height Z-score \pm SEM & Range & $n(\mathrm{~F} / \mathrm{M})$ & Height Z-score \pm SEM & Range \\
\hline I & $73(38 / 35)$ & $-1.27 \pm 0.16$ & -6.35 to 1.10 & $33(15 / 18)$ & $-1.19 \pm 0.15$ & -3.3 to 0.65 \\
\hline IV & $6(2 / 4)$ & $-3.56 \pm 0.79$ & -6.46 to -1.51 & $4(3 / 1)$ & $-4.60 \pm 1.05$ & -7.08 to -1.99 \\
\hline V & $4(1 / 3)$ & $-0.67 \pm 0.27$ & -1.41 to -0.23 & $3(3 / 0)$ & $-1.29 \pm 0.96$ & -3.16 to 0.04 \\
\hline
\end{tabular}

Ol, osteogenesis imperfecta. 
Table 3. Height Z-scores of study cohort compared to prior reports

\begin{tabular}{|c|c|c|c|c|c|c|c|c|c|c|c|c|c|}
\hline & \multirow[b]{2}{*}{ Type } & \multicolumn{2}{|c|}{$\begin{array}{l}\text { Germain-Lee et al. } \\
\text { (present study) }\end{array}$} & \multicolumn{2}{|c|}{$\begin{array}{c}\text { Engelbert et al. (36) } \\
\text { (2004) }\end{array}$} & \multicolumn{2}{|c|}{$\begin{array}{c}\text { Zeitlin et al. (7) } \\
\text { (2003) }\end{array}$} & \multicolumn{2}{|c|}{$\begin{array}{c}\text { Glorieux et al. (25) } \\
(2000)\end{array}$} & \multicolumn{2}{|c|}{$\begin{array}{l}\text { Lund et al. (5) } \\
\text { (1999) }\end{array}$} & \multicolumn{2}{|c|}{$\begin{array}{c}\text { Engelbert et al. } \\
\text { (37) (1998) }\end{array}$} \\
\hline & & $N$ & Z-score & $n$ & Z-score & $n$ & Z-score & $n$ & Z-score & $n$ & Z-score & $n$ & Z-score \\
\hline & III & 34 & -6.45 & 13 & -8.4 & 47 & -6.8 & & & 10 & -6.2 & 16 & -8.0 \\
\hline & IV & 10 & -3.98 & 14 & -3.4 & 47 & -3.4 & 8 & -3.0 & 8 & -3.2 & 14 & -2.8 \\
\hline & III & 36 & -8.90 & & & & & & & 5 & -10.6 & & \\
\hline & IV & 26 & -4.61 & & & & & & & 14 & -3.4 & & \\
\hline & V & 9 & -4.36 & & & & & & & & & & \\
\hline
\end{tabular}

a

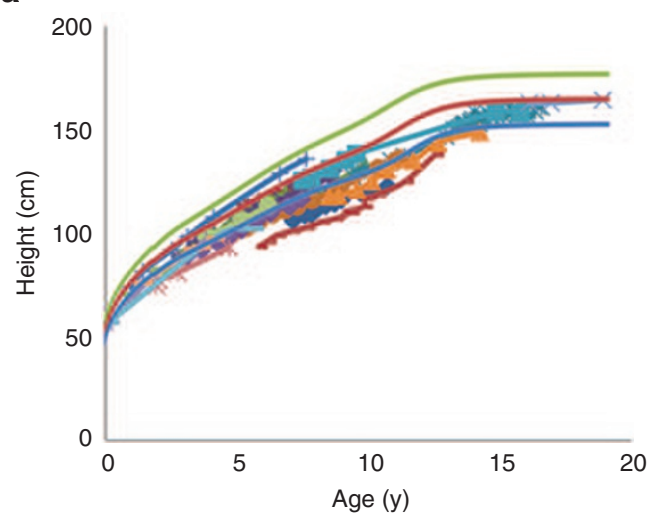

C

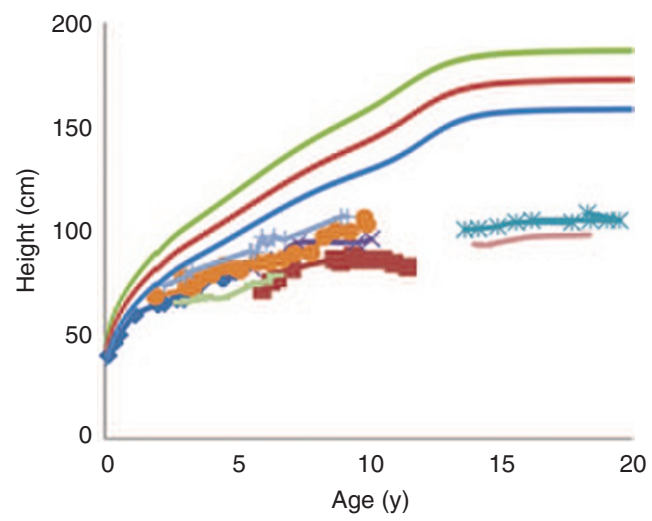

b

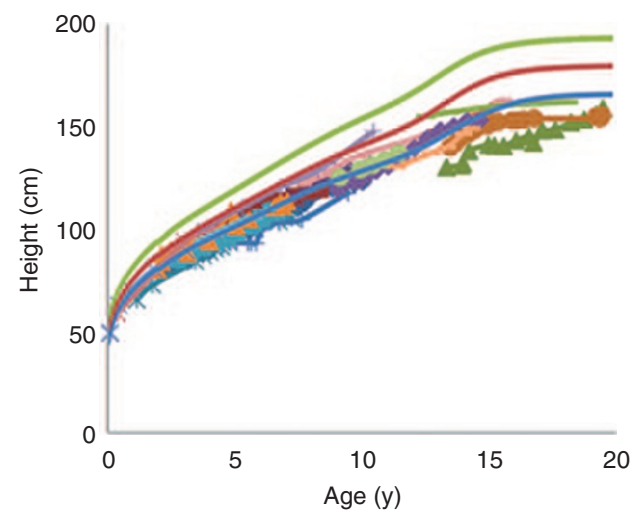

d

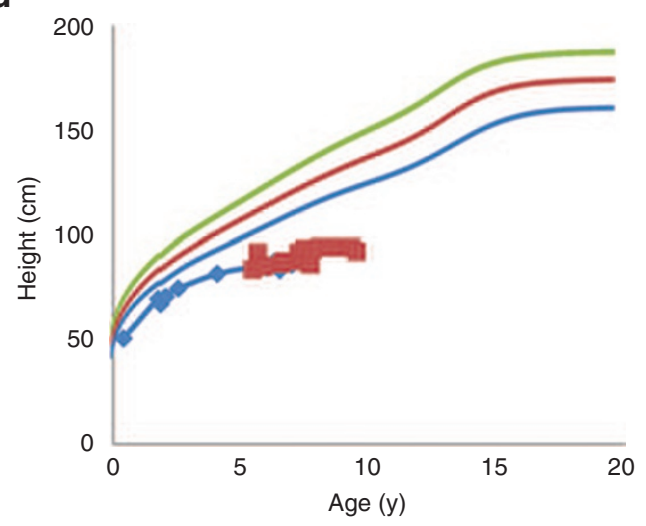

Figure 3. Longitudinal growth pattern in children with type I and type III osteogenesis imperfecta $(\mathrm{OI})$ with standard percentile chart (green curve $=97$ th percentile, red curve $=50$ th percentile, blue curve $=3$ rd percentile. Note: Standard percentile curve shows CDC percentiles for all ages. (a) Girls with OI type I $(n=18)$; (b) boys with OI type I $(n=18)$. (c) Girls with OI type III $(n=8)$. (d) Boys with OI type III $(n=2)$.

of these skeletal abnormalities. In an anthropometric study of OI, the heights of patients of all OI types were lower than the heights of unaffected family members and followed the distribution of heights within each type, thereby suggesting that the collagen defect itself could be the etiology of the impaired growth (5). Although the heights may be considered "normal" in type I OI, children and adults with type I have lower mean adult height standard deviation scores (height SDS) than the general population, with a mean final adult height SDS of -1.49 in the adults in our cohort. In addition, patients with OI type IV grow very similarly to those with type III during the first 10 $y$ of life with the same extent of fractures and skeletal deformities but have only mild to moderate growth impairments as adults, again indicating that other factors are involved in linear growth in OI (6). It has been speculated that the teleological basis for the short stature could be "self-protective," especially in severe OI in which there is markedly reduced stature; i.e., a shorter bone would not fracture as easily as a longer one $(7,12)$.

Although it is obvious that recurrent fractures, worsening scoliosis, and vertebral compression contribute to a decrease in height, there are other factors that contribute. It has been theorized that abnormalities in the transition from cartilage to 
a

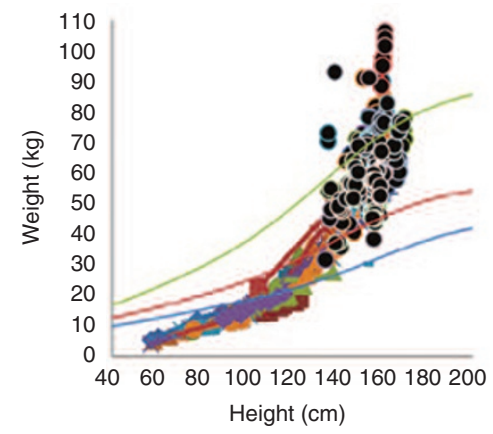

d

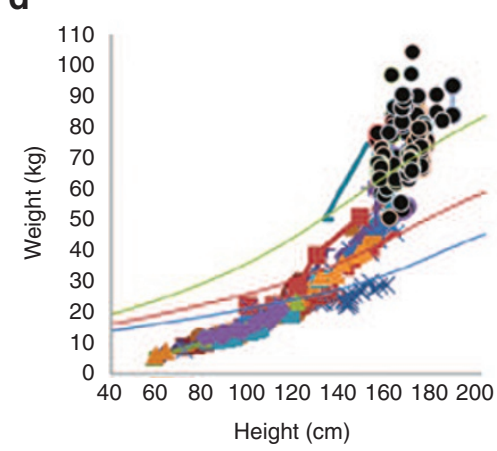

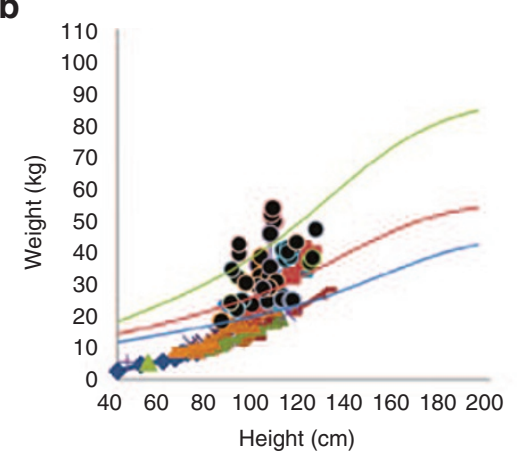

e

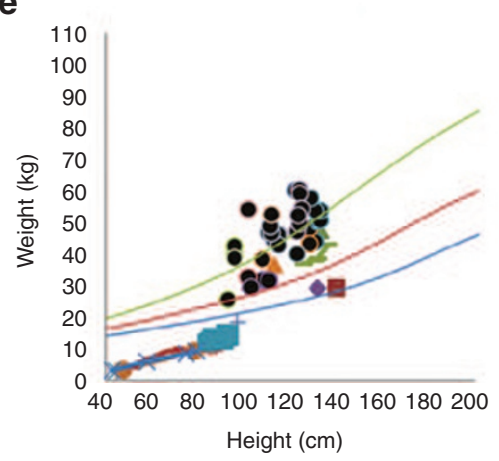

C

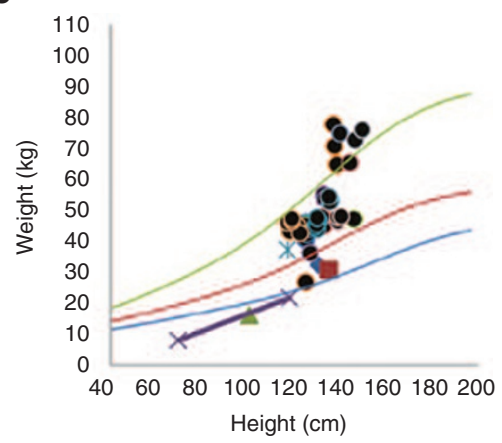

f

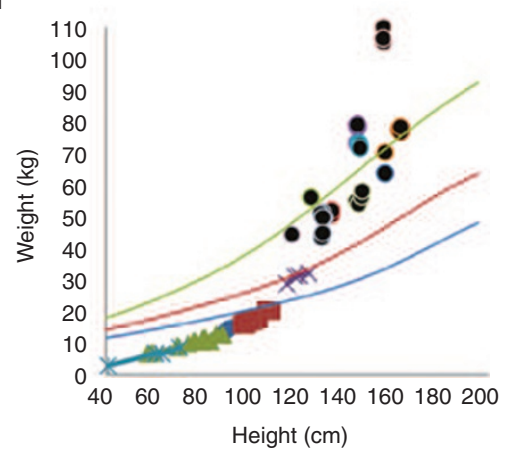

Figure 4. Relationship between height and weight in children and adults with osteogenesis imperfecta (OI) types I, III, and IV. Pediatric data (age <20) is multicolored and adult data (age $\geq 20$ ) is black (different color for each participant). Standard weight-for-height percentile chart (CDC data): green curve $=97$ th percentile, red curve $=50$ th percentile, blue curve $=3$ rd percentile. Note: Standard percentile curve shows CDC percentiles for all ages. (a) Females with OI type I $(n=131)$. (b) Females with OI type III $(n=42)$. (c) Females with OI type IV $(n=20)$. (d) Males with OI type I ( $n=92)$. (e) Males with Ol type III $(n=28)$. (f) Males with OI type IV $(n=16)$.

bone as is seen in OI could have a negative impact on growth (15). Linear growth patterns have been found to be consistent with what would be predicted based on the severity of the OI type $(5-7,12,29)$. In our cohort, we found that children with type I OI have birth lengths within the normal range, but the height percentiles gradually decrease to the subnormal range in childhood with final adult heights ending up slightly below the normal height range. In type IV OI, birth lengths were also normal but by 2 y of age, the growth had decelerated and remained poor throughout childhood, with final heights affected to a moderate degree. In type III OI, the infants were of short to normal lengths with very poor growth velocities and severely compromised heights once reaching adulthood. Vetter et al. (6) examined 127 children (40 type I, 39 type II, and 48 type IV) and found that the birth weights and lengths of type III patients were significantly lower than in types I and IV, consistent with our findings, which raises questions as to whether the negative impact on growth in severe OI begins in utero.

The pattern of OI patients' adult height Z-scores being lower than their corresponding pediatric Z-scores is common to many diseases that alter normal growth, as well as to any conditions in which there is an early pubertal onset. In OI, the difference in pediatric vs. adult height $\mathrm{Z}$-scores may be reflective of the absent/decreased pubertal growth spurt that we have described here, although pubertal progression is normal. It is also possible that patients with OI plateau in their growth due to the condition itself-i.e., a chronic disease with increased caloric needs for appropriate linear growth. In a recent study examining patients' energy requirements, OI type III had a higher percentage of energy intake, possibly indicating an increased caloric need (24). The obesity that develops over time could simply be a result of the sedentary lifestyle that is a result of the condition, which is typified by recurrent fractures, pain, skeletal abnormalities, and severe scoliosis with resultant wheelchair dependence.

In our patient population, $60 \%$ received bisphosphonate therapy. However, the therapy was given at varying ages and periods of time, thereby limiting our ability to make any general conclusions about treatment effect on height or weight. We examined the height and weight $\mathrm{Z}$-scores as well as the growth velocity in those who were treated over the course of therapy, as well as before and $1 \mathrm{y}$ after, in each subject and found no significant individual differences in these parameters over the course of treatment. When we examined the treated and untreated subjects among all OI types for final height and weight $\mathrm{Z}$-scores there were no differences, but again, the subjects were treated for varying lengths of time so these data are limited in their interpretation. Several studies have reported on vertebral height after bisphosphonate treatment. Sakkers et al. (19) did not find any differences in radiographic assessments of lumbar vertebral heights between olpadronate and placebo at 24 mo of follow up. Other studies have found statistically significant increases in height Z-scores in response to 12 
mo of alendronate, risedronate, and intravenous pamidronate therapy, respectively (20-22). However, none of these studies analyzed the outcome measure of final height, which is the true measure of clinical effect on linear growth. Clearly, the role of bisphosphonate treatment on final adult height in patients with OI needs further investigation.

As we have demonstrated, being overweight or obese is common for patients with OI, although the literature is sparse on this topic. Chagas et al. (23) reported 13 patients with type III OI (mean age $=20 \mathrm{y}$ ) having a significantly higher body mass index $(28.8 \pm 6)$ compared to patients with type I OI and controls with $46 \%$ classified as obese. Zambrano et al. (24) recently reported an association between being overweight or obese and the type of OI, especially prominent in the severe phenotypes. In addition, there was a higher percentage of energy intake in OI type III (24). They recommended individualized nutritional support. We found that obesity occurs in type I and type IV OI as well, although our data revealed that patients with type III were by far the most severely affected group. In fact, when taller than approximately $100 \mathrm{~cm}$, the increases in the subjects' weight-for-height were most noticeable. Although Vetter et al. (6) examined 127 children with OI type I, III, or IV and found that the birth weights and lengths of OI type III children were the lowest, and Zeitlin et al. (7) found weight Z-scores to be lowest in childhood in OI type III patients, we found that the weight in type III OI clearly increases dramatically over time as the linear growth velocity decelerates and obesity is an issue of concern later in life.

Obvious reasons for being overweight/obese in OI include decreased mobility due to fractures, existing skeletal abnormalities, and pain, often leading to wheelchair dependence as in type III OI. A recent cross-sectional study of 62 children and adolescents with varying types of OI demonstrated that moderate and severe forms of OI are associated with greater functional impairment, influenced by fracture history, which has a negative impact on ambulation and the ability to improve with physical therapy (30). It would be reasonable to think that the more severe the functional impairment, as in OI type III, the more dramatic the weight gain secondary to the decreased functional capabilities.

Whatever the underlying etiology for the development of obesity in our patient population may be, our findings indicate a need for weight control measurements as well as the importance of dietary measures in patients with OI. In addition, a constant assessment of the factors contributing to the accelerated weight gain, such as decreased mobility and/or increased caloric intake, is necessary.

The impact of OI on skeletal muscle function and anatomy has only received limited investigation. The muscle-bone interaction is important for bone health, and not only can improvements in muscle strength improve stability and exercise tolerance, but the tensile action of muscle on bone is itself a positive force in improving bone density (31-33). Appropriate physical therapy and exercise could lead to stronger bone and potentially fewer fractures, thereby improving the amount of time that the patient with OI is mobile.
The linear growth patterns, in addition to the marked increase in weight over time, indicate a need for functional modifications as early as childhood in patients with OI, especially a need for weight control. It is clear that the etiological determinants of height, weight, and overall growth patterns are multifactorial in OI, and the relationship of the anthropometric abnormalities to defective collagen, impaired mobility, metabolism, and nutritional factors in OI requires further investigation.

\section{METHODS}

This research was approved by the Johns Hopkins Institutional Review Board (IRB) of Johns Hopkins Medicine (Baltimore, MD). Subject informed consent and/or parental informed consent for subjects younger than 18 y of age was obtained. For both cross-sectional and longitudinal analysis of anthropometric measures, data were collected from the medical records of patients with a diagnosis of OI who were seen in the Osteogenesis Imperfecta Clinic at the Kennedy Krieger Institute (Baltimore, MD) from 2004 to 2013. Subjects were classified as having one of five types of OI initially categorized by Sillence (3) and refined by Glorieux et al. (25) to include type V. Subjects classified as type I OI are characterized by having blue sclerae, absent or minimal limb deformities, and being fully ambulatory. Subjects classified as type III or type IV have short stature, white or blue sclerae, scoliosis, and limb deformities that are considered severe enough to impair normal ambulation and require constant use of a wheelchair (type III) or the use of a cane or walker (type IV). Subjects with type V have white sclerae, $\mathrm{x}$-ray evidence of hyperplastic callous formation, and dislocated radial heads.

Height and weight measurements were performed by physicians and nurses experienced in caring for patients with OI who may have skeletal deformities. Obvious data entry errors were eliminated, and the majority of subjects had greater than three separate measurements. Standing heights were performed using a Harpendon stadiometer (Holtain, Crymych, Dyfed, UK) or a digital Tanita HR-200 stadiometer (Arlington Heights, IL), each calibrated every 6 mo. For a subgroup of subjects with OI type III either arm span measurements or recumbent lengths were obtained on a standardized recumbent measuring device (Hopkins Medical Products Measure Mat II, Baltimore, MD) when standing heights could not be performed due to fractures and/or deformities. Weights were performed on either a Scaletronix standing scale or a specialized Scaletronix chair scale for subjects unable to stand (White Plains, NY). For infants, a separate Pediatric Scaletronix scale was utilized. As per the CDC and American Academy of Pediatrics, the World Health Organization growth criteria were used to analyze the growth data for children between the ages of $0-2 \mathrm{y}(34)$, while for children $2 \mathrm{y}$ of age and over, the Center for Disease Control guidelines were utilized (35).

Height Z-scores were computed based on the L, M, S parameters published by the CDC (35). Height Z-scores for adults were computed using the parameters published for patients 240 mo of age $(20 \mathrm{y}$ and $0 \mathrm{mo}$ ), the oldest subset for which such parameters are available. Because of this, we considered all subjects less than $20 \mathrm{y}$ of age as children and all subjects $20 \mathrm{y}$ of age or older as adults. Data were not adjusted to account for loss of height with increasing age, as the available estimators are used infrequently in the literature, and no estimator is available for those with OI. The mean HVSDS was calculated by utilizing http://growthcalc.chip.org/GrowthCalc (Growth Calculator 2.01, Dan Nigrin, M.D., Children's Hospital Boston, Boston, MA).

\section{ACKNOWLEDGMENT}

The authors thank the patients and their families.

\section{STATEMENT OF FINANCIAL SUPPORT}

This research was funded by the Charitable Research Foundation, Punta Gorda, Florida and The Edward W. and Stella C. Van Houten Memorial Fund, New Jersey.

Disclosure: There are no conflicts of interest, real or perceived. 


\section{REFERENCES}

1. Cundy T. Recent advances in osteogenesis imperfecta. Calcif Tissue Int 2012;90:439-49.

2. Eyre DR, Weis MA. Bone collagen: new clues to its mineralization mechanism from recessive osteogenesis imperfecta. Calcif Tissue Int 2013;93:338-47.

3. Sillence DO, Senn A, Danks DM. Genetic heterogeneity in osteogenesis imperfecta. J Med Genet 1979;16:101-16.

4. Sillence DO, Lamande SR. Evolution of the present understanding of the clinical and genetic heterogeneity and molecular and biochemical basis of osteogenesis imperfecta. In: Shapiro JR, Byers PH, Glorieux FH, Sponseller PD, eds. Osteogenesis Imperfecta: A Translational Approach to Brittle Bone Disease. London, UK: Academic Press, is an imprint of Elsevier, 2014: $5-14$.

5. Lund AM, Müller J, Skovby F. Anthropometry of patients with osteogenesis imperfecta. Arch Dis Child 1999;80:524-8.

6. Vetter U, Pontz B, Zauner E, Brenner RE, Spranger J. Osteogenesis imperfecta: a clinical study of the first ten years of life. Calcif Tissue Int 1992;50:36-41.

7. Zeitlin L, Rauch F, Plotkin H, Glorieux FH. Height and weight development during four years of therapy with cyclical intravenous pamidronate in children and adolescents with osteogenesis imperfecta types I, III, and IV. Pediatrics 2003;111(5 Pt 1):1030-6.

8. Rauch F, Glorieux FH. Osteogenesis imperfecta, current and future medical treatment. Am J Med Genet C Semin Med Genet 2005;139C: $31-7$.

9. Land C, Rauch F, Glorieux FH. Cyclical intravenous pamidronate treatment affects metaphyseal modeling in growing patients with osteogenesis imperfecta. J Bone Miner Res 2006;21:374-9.

10. Rauch F, Glorieux FH. Treatment of children with osteogenesis imperfecta. Curr Osteoporos Rep 2006;4:159-64.

11. Rauch F, Cornibert S, Cheung M, Glorieux FH. Long-bone changes after pamidronate discontinuation in children and adolescents with osteogenesis imperfecta. Bone 2007;40:821-7.

12. Plotkin H. Growth in osteogenesis imperfecta. Growth Genet Horm 2007;23:17-23.

13. Ben Amor IM, Glorieux FH, Rauch F. Genotype-phenotype correlations in autosomal dominant osteogenesis imperfecta. J Osteoporos 2011;2011:540178.

14. Martin E, Shapiro JR. Osteogenesis imperfecta:epidemiology and pathophysiology. Curr Osteoporos Rep 2007;5:91-7.

15. Forlino A, Cabral WA, Barnes AM, Marini JC. New perspectives on osteogenesis imperfecta. Nat Rev Endocrinol 2011;7:540-57.

16. Glorieux FH. Osteogenesis imperfecta. Best Pract Res Clin Rheumatol 2008;22:85-100.

17. Plotkin H. Syndromes with congenital brittle bones. BMC Pediat 2004;4:16.

18. Germain-Lee EL, DiGirolamo D, Plotkin H. Growth and growth hormone use in osteogenesis imperfecta. In: Shapiro JR, Byers PH, Glorieux FH, Sponseller PD, eds. Osteogenesis Imperfecta: A Translational Approach to Brittle Bone Disease. London, UK: Academic Press, is an imprint of Elsevier, 2014: 267-80.

19. Sakkers R, Kok D, Engelbert R, et al. Skeletal effects and functional outcome with olpadronate in children with osteogenesis imperfecta: a 2-year randomised placebo-controlled study. Lancet 2004;363:1427-31.
20. Seikaly MG, Kopanati S, Salhab N, et al. Impact of alendronate on quality of life in children with osteogenesis imperfecta. J Pediatr Orthop 2005;25:786-91.

21. Bishop N, Adami S, Ahmed SF, et al. Risedronate in children with osteogenesis imperfecta: a randomised, double-blind, placebo-controlled trial. Lancet 2013;382:1424-32.

22. Letocha AD, Cintas HL, Troendle JF, et al. Controlled trial of pamidronate in children with types III and IV osteogenesis imperfecta confirms vertebral gains but not short-term functional improvement. J Bone Miner Res 2005;20:977-86.

23. Chagas CE, Roque JP, Santarosa Emo Peters B, Lazaretti-Castro M, Martini LA. Do patients with osteogenesis imperfecta need individualized nutritional support? Nutrition 2012;28:138-42.

24. Zambrano MB, Brizola ES, Refosco L, Giugliani R, Félix TM. Anthropometry, nutritional status, and dietary intake in pediatric patients with osteogenesis imperfecta. J Am Coll Nutr 2014;33:18-25.

25. Glorieux FH, Rauch F, Plotkin H, et al. Type V osteogenesis imperfecta: a new form of brittle bone disease. J Bone Miner Res 2000;15:1650-8.

26. Marini JC, Bordenick S, Chrousos GP. Endocrine aspects of growth deficiency in OI. Connect Tissue Res 1995;31:S55-7.

27. Sillence DO, Barlow KK, Cole WG, Dietrich S, Garber AP, Rimoin DL. Osteogenesis imperfecta type III. Delineation of the phenotype with reference to genetic heterogeneity. Am J Med Genet 1986;23:821-32.

28. Rowe D, Shapiro J. Osteogenesis imperfecta. In: Avioli LV, Krane SM, eds. Metabolic Bone Disease and Clinically Related Disorders. 3rd edn. Philadelphia, PA: W.B. Saunders Co., 1990: 651-95.

29. Plotkin H, Primorac D. Osteogenesis imperfecta. In: Glorieux FH, Pettifor JM, Jüppner H, eds. Pediatric Bone: Biology \& Diseases. Amsterdam, Netherlands: Elsevier/Academic Press, 2003: 443-71.

30. Brizola E, Staub AL, Félix TM. Muscle strength, joint range of motion, and gait in children and adolescents with osteogenesis imperfecta. Pediatr Phys Ther 2014;26:245-52.

31. Caudill A, Flanagan A, Hassani S, et al. Ankle strength and functional limitations in children and adolescents with type I osteogenesis imperfecta. Pediatr Phys Ther 2010;22:288-95.

32. Takken T, Terlingen HC, Helders PJ, Pruijs H, Van der Ent CK, Engelbert RH. Cardiopulmonary fitness and muscle strength in patients with osteogenesis imperfecta type I. J Pediatr 2004;145:813-8.

33. Veilleux LN, Lemay M, Pouliot-Laforte A, Cheung MS, Glorieux FH, Rauch F. Muscle anatomy and dynamic muscle function in osteogenesis imperfecta type I. J Clin Endocrinol Metab 2014;99:E356-62.

34. de Onis M, Onyango AW, Borghi E, Garza C, Yang H; WHO Multicentre Growth Reference Study Group. Comparison of the World Health Organization (WHO) Child Growth Standards and the National Center for Health Statistics/WHO international growth reference: implications for child health programmes. Public Health Nutr 2006;9:942-7.

35. Kuczmarski RJ, Ogden CL, Grummer-Strawn LM, et al. 2000 CDC growth charts for the United States: methods and development. Vital Health Stat 2002;11:1-190.

36. Engelbert RH, Uiterwaal CS, Gerver WJ, van der Net JJ, Pruijs HE, Helders PJ. Osteogenesis imperfecta in childhood: impairment and disability. A prospective study with 4-year follow-up. Arch Phys Med Rehabil 2004;85:772-8.

37. Engelbert RH, Gerver WJ, Breslau-Siderius LJ, et al. Spinal complications in osteogenesis imperfecta: 47 patients 1-16 years of age. Acta Orthop Scand 1998;69:283-6. 